\title{
Geoestética de idas-vueltas (a modo de introducción)
}

\author{
Soulages, François
}

"El éter tiene esa curiosa propiedad de recordarme un sufrimiento para borrarlo en seguida". Memoria y olvido. Patrick Modiano (2013, p. 842)

Geoartística-geoestética, idas-vueltas

Todo empieza con lo artístico, mejor dicho con lo geoartístico de Reprises, obra de Alejandro Erbetta, fotógrafo y teórico argentino cuya familia es italiana de origen: su trabajo es teórico y fotográfico a la vez, sobre el paso de las fronteras, es un ida-vuelta entre Argentina e Italia/Europa. Parte de una historia individual, familiar y colectiva, la suya, la de su familia pero también la de todos esos italianos, nacionalizados argentinos de los cuales algunos descendientes volvieron a Europa, como el Papa Francisco. Reconstruye la historia de su familia de origen italiana, que emigraron a la Argentina en los años 1885. Fotografías sacadas de los álbumes y de los relatos familiares 1 se entrecruzan con las fotos de sus propios viajes por la región origen de sus bisabuelos -el norte de Italia-, e igualmente por archivos y documentos

Cuadernos del Centro de Estudios de Diseño y Comunicación Nº 59

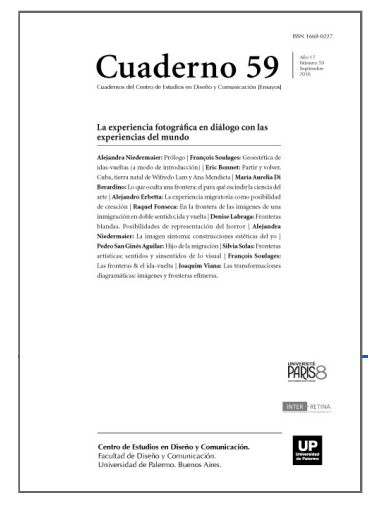

ISSN: 1668-0227

La experiencia

fotográfica en diálogo

con las experiencias

del mundo

descargar PDF

ver índice de la publicación

Ver todos los libros de la publicación

compartir en Facebook

Año XVII, Septiembre 2016, Buenos

Aires, Argentina | 172 páginas

históricos encontrados en el sitio

mismo. Los relatos, la memoria

y su "país natal" diría además Modiano, su lugar presente, su "lugar natural" diría Aristóteles, su "casa" diría E.T., Argentina, Argentón diría Bernard Koest, porque parece que siempre existe un retorno posible, aunque sea el de un reprimido, a no ser que sea el trayecto de una vida, o sea la obra de toda una vida. Cristóbal Colón ha vuelto también.

A cualquier ser humano le concierne el problema universal del ir y del volver, del fort/da2.

La migración de los cuerpos y de las almas

Y, en particular, el migrante que viene, que va. Que viene de alguna parte; y si no es él, es pues su hermano, su padre, el padre de su padre, etc.

"-Si no eras tú, sería tu hermano.

No tengo hermanos. - Entonces fue alguno de los tuyos:

Porque no me perdonan en absoluto,

Usted, sus pastores ni sus perros.

Lo han dicho y necesito vengarme".

Dicho esto, a lo profundo del bosque

El lobo se lo lleva y se lo come,

Sin más proceso de juicio". (La Fontaine)3

Existe riesgo y violencia para el migrante, el emigrado, el inmigrado.

El migrante que sueña volver al país. ¿Qué país? El ¿suyo? A menudo, no ha nacido allí.

¿Cuál es su país? ¿El de sus antepasados, el que le permite centrarse en sus antepasados? 
Realidad e imaginario nutren su sueño, su sueño de cruzar de nuevo las fronteras, en el otro sentido, hacer lo que su padre y sus antepasados no han hecho, ser el que ha vuelto, o más exactamente, el que ha vivido y ha jugado con el ida-vuelta, con el "a la vez", porque es una dupla como lo sugería Platón: no solamente el que sueña, sino también el que piensa:

Pensar (:) un discurso [logos] cuya alma se mantiene siempre sobre los objetos que examina. (...) El alma en su acto de pensar; no es otra cosa sino dialogar, dirigirse a sí mismo las preguntas y las respuestas, pasando de la afirmación a la negación. (Platón, 1976)

Efectivamente, se trata del pensamiento y por ende de la humanidad. El pensador, como cualquier ser humano, es un migrante que se encuentra en el ida-vuelta, el hombre de las dos orillas; es por lo que los Griegos llamaban a los hombres "los mortales", no tanto porque tenían que morir, sino porque eran a su vez vivos presentes y muertos futuros, son ida-vuelta, son 'a la vez' mamíferos que entierran sus muertos que viajan hacia el reino de los muertos, si le creemos al Libro de los muertos de los Antiguos Egipcios y cuyo título exacto era Libro para Salir a la Luz:

O dioses quienes tiráis de la barca del maestro de los millones de años, quienes lleváis el cielo a la Douat, quienes alejáis el cielo inferior, quienes hacéis que las almas se acerquen a las momias, que vuestras manos mantengan vuestras cuerdas (...) y hacéis que este alma del (difunto que soy) suba hacia los dioses bajo vuestros traseros, del horizonte oriental del cielo, para acompañar hasta el lugar donde estaba ayer, jen paz, en paz, en Occidente!

¡Qué vea su cuerpo, qué descanse sobre su momia! (Así) no morirá, no será aniquilado, jamás. (Barguet, 1967, p. 126)

\section{Y Homero quien dice, mucho después:}

"Pero es necesario, ante todo, emprender otro viaje Hacia las casas de Hades y de la gran Perséfone". (Homero, 1992, p. 173)

\section{Las fronteras}

Las fronteras, cuando uno es un hombre, a menudo, están hechas para ser cruzadas. Puesto que ellas nos confrontan a nuestra finitud queremos experimentar e imaginar que podemos superarlas; al menos superamos las fronteras y entonces ya no hay fronteras para el ser humano.

A finales del siglo XIX, cincuenta millones de europeos emigraron hacia las Américas, muchos partieron para América Latina; $y$, a principios del siglo XXI, tres millones de descendientes de esos migrantes de América del Sud volvieron a Europa. Y el mismo fenómeno ocurre por razones diversas en todo el globo.

¿Cuáles son las razones? ¿Para encontrar trabajo, para realizar estudios, para vivir mejor, para encontrar una nueva estabilidad, o bien por vivir también un ida-vuelta? Estimulante ida-vuelta.

¿Por cuestiones meramente materiales y económicas o también por razones intelectuales, espirituales, imaginarias, que interrogan la memoria, el pasado, la identidad, la transmisión, el ida-vuelta en sí-mismo? Entonces, las relaciones y las tensiones entre fronteras se viven y se plantean a partir de esos ida-vuelta. Irvolver material, pero también reflexivo, poético, artístico, nostálgico, existencial. Las mujeres y los hombres que lo viven se nutren de ello día a día y, artistas e intelectuales se interrogan creando obra.

El ida-vuelta puede producir dos destinos: lo único y lo plural. El único es un ir seguido de un volver: Ulises, du Bellay. Lo plural es seguido de un otro ida-vuelta, luego otro, hasta el infinito... No es la experiencia de la bilocación, sino la doble pertenencia a dos lugares, dos culturas, dos nacionalidades; mejor aún, se trata de la experiencia del tiempo que permite, a la vez, ir-volver, de estar aquí, luego allí, que permite dejar de ser para abrazar el futuro. El ida-vuelta -y su geoestética-, es el fracaso, el fin de Parménides:

El Ser es no -creado, imperecedero, puesto que solo es completo, inmóvil y eterno. (...) Es en su totalidad idéntico a él mismo (...) Es sin comienzo y sin fin. (...) Permanece idéntico a él mismo, en el mismo estado es por él mismo. (Parménides, pp. 94-95)

Con este filósofo, el cambio no es pensado, el tiempo tampoco, el ir, el volver, tampoco la ida-vuelta -al menos sin tener en cuenta la metamorfosis, siempre trágica de lo existente, o sea de la existencia; la vida y el ser son pensados, sin fronteras, sin límites, sin obstáculos, sin finitud, sin muerte; la existencia no está pensada.

Sin embargo, ¿ese sueño de ida-vuelta es la victoria de Heráclito? No automáticamente, puesto que este sueño se encuentra, a veces, habitado por la creencia del lugar reencontrado, del tiempo reencontrado, del eterno regreso como regreso idéntico a sí mismo. De nuevo, lo trágico es evacuado, la existencia no es tenida seriamente en cuenta en su existir.

Es creer en la resurrección olvidando el Viernes Santo: Cristo ya no era el mismo cuando resucitó; no realizó un ida-vuelta Cielo-Tierra.

Efectivamente, ir-volver cuando se encuentra en su acmé (plenitud) -en la vida, como en el arte- no es la negación de la transformación, la puesta entre paréntesis del tiempo, al contrario es la asunción de lo trágico del 
tiempo y la encarnación de la transformación así como la movilidad sensible e inteligible de un lugar a otro lugar. Lugares que se reconstruyen por el tiempo y por el sujeto a través del tiempo, sobre todo cuando se es artista. Heráclito nos ayuda para aclarar: "Todo fluye" (Heráclito,1986, p. 467). Ir-volver es un fluir del tiempo y del espacio gracias a un movimiento espiralado en el espacio-tiempo: no se vuelve, no se retorna, no se revisita, no se repite: "Uno no puede bajar dos veces por el mismo río". (Heráclito, frag. 105, p. 44)

Entonces, uno puede experimentar el tiempo: "El tiempo es un niño que juega desplazando fichas: es el reinado de un niño" (Heráclito, frag. 130, p. 446). El ida-vuelta es un desplazamiento de unas fichas realizado por un niño que juega al regreso, pero que sabe que va a otra parte. A la nostalgia y la falta, por ende al deseo reiniciado sin fin, al erotismo del viaje. En ocasiones, a la melancolía. Es decir, siempre el ejercicio de lo sensible, de la imaginación y sobre todo del pensamiento. Efectivamente, el ida-vuelta de la diferencia permite crear lazos con las cosas, dialogar en el sentido en el que lo entiende Platón; y sin él, no hay pensamiento, puesto que no hay escucha. Heráclito lo había entendido:

"No sabiendo tampoco escuchar, tampoco sabían hablar" (Heráclito, p. 50). El ida-vuelta aprende a hablar, a no ser ya el infans, a entrar en el logos -palabra, lógica, pensamiento. Modiano lo entendió dos mil años y medio tras el Efesio.

\section{Universalización}

Sin embargo, estos ida-vuelta caracterizan no solo la vida de estos tres millones de migrantes de América del Sur, sino también a cualquier ser humano cuando, en un momento de su vida, realiza siempre un retorno sobre el camino recorrido por él mismo, su familia y los grupos de origen.

De este modo, a partir de la reflexión y la creación, las causas se entienden mejor, las modalidades y los retos de esos ir-volver plurales expresan, cierto es, un momento peculiar de la migración, una travesía individual de las fronteras, una manera específica de vivir el espacio, pero sobre todo y ante todo, una manera específica de vivir el tiempo y en el tiempo, el pasado, el presente y el futuro, simplemente de vivirlo uno-mismo.

A su vez, el término "Fronteras" puede ser interpretado en distintos sentidos. Por ejemplo, desde la perspectiva artística y estética: demos algunos ejemplo: Alejandro Erbetta con Fronteras y memorias4, Bernard Koest con Argenton-Argentine, 2014, Borges con Ficciones, Modiano con toda su obra.

Geopolítica \& geoartística, ida-vuelta

\section{Geoartística}

Las obras que trabajan la problemática Fronteras y migraciones, ida-vulelta se confrontan en lo geoartístico y lo geopolítico; son la consecuencia y la expresión. El arte no está aislado: la expansión de lo geoeconómico y de lo geopolítico produce lo geoartístico y lo geoestético.

Lo geoartístico caracteriza algunas prácticas del arte y algunos desplazamientos de artistas5.

¿Cuándo? Muy a menudo en el transcurso de la Historia: por ejemplo, Alejandro, Roma, el Renacimiento, San Petersburgo, hoy... ¿Cómo? Con formas diferentes, en función de la historia (del arte) y de la geografía (del arte): ¿No será la geografía del arte más importante que su historia6? Lo geoartístico indica pues un desplazamiento, voluntario o no, de un artista, de una práctica artística, de una corriente artística; por otra parte, una corriente artística corre y se desplaza, en caso contrario, no sería una corriente, sino un estacionamiento, una capilla para débiles creyentes que necesitan algo maternal, sentirse tranquilos, algo paternal y poder contar su pasado como si fuese un eterno presente: jah los antiguos combatientes del arte contemporáneo! Entonces lo geoartístico es una característica del arte actual, de su mutación, algunos dirían de su "crisis": la última Trienal de París de 2012 se opuso a estos estacionamientos y nostalgias para mostrarnos y ayudarnos a interrogar obras cuestionando las fronteras -así como las paradójicas rejas rayadas de Daniel Buren- y la globalización: ¿de cómo vivimos estas desconexiones con todas las formas del etnocentrismo, lo religioso u otros?", pregunta el comisario de la exposición, el americano de origen nigeriano Okwui Enwezor que desea "analizar este género de prueba que padece hoy la universalidad"7. Las fronteras prohíben a veces la universalidad en provecho de lo híbrido contemporáneo que une, paradójicamente a veces, la uniformidad y lo comunal. "En la interconexión de estos mundos múltiples, la globalización nos obliga a admitir la crisis de la universalidad"8. No se equivoca, salvo que, cuando se produjo esta universalidad, ¿representaba su sentimiento total? Los desafíos de las fronteras -geoartísticas comprendidas también, como geopolíticas- no son tan civilizatorias en relación a la humanidad misma sino que albergan un valor notable e irremplazable -poder pasar de lo particular a lo universal, por lo tanto se puede pensar y no simplemente reaccionar: el otro ya no es sólo el otro, sino el prójimo, ego y ser humano como yo, mi igual. La humanidad es la universalidad, la igualdad y la capacidad de pensar -Sócrates lo ha demostrado a partir del pequeño esclavo de Menón: igualdad y no identidad, de iure y no de facto, ontológico y filosófico y no superficial y pragmático. "El malestar actual me parece es pues, escribía Paul Valéry antes de la segunda guerra mundial, una crisis del espíritu, una crisis de los espíritus y de las cosas del espíritu"

9. Habría que releer a Husserl.

Desplazamientos, deslocalizaciones, descentramientos

Es por eso que para participar de estas luchas y no ser víctimas de estas transformaciones, 
es que se operan desplazamientos y deslocalizaciones geoartísticas de ida-vuelta. ¿Pero dónde y cómo? Lo geoartístico está marcado siempre por una movilidad en el espacio.

¿Qué espacio(s)? El espacio geográfico, entonces geopolítico, y el espacio artístico. Pensar a partir de lo geoartístico, es pues pensar a partir del mundo, de la geografía habitada por la historia, de las geografías habitadas por las historias; es pues igualmente hablar de geopolítica: el problema de las fronteras geoartísticas está articulado con las fronteras geopolíticas y esclarece lo que se ha dado, antaño, en llamar "los tiempos de crisis".

Los artistas entonces se desplazan por el espacio; pero ¿por elección o por necesidad? Por "elección" -pero volvamos a leer el Apéndice de la Ética I de Spinoza...-, dejan su espacio donde han nacido, que no siempre coincide con el espacio donde han nacido sus padres y madres, y van a Roma, a París, a Nueva York, a Pekín, en Internet: amplían su espacio exterior $-\mathrm{y}$, correlativamente, su espacio interior- y sobre todo exploran el espacio, circulan dentro, lo construyen y se lo apropian para realizar obra de otro modo. Internet, alto exponente del ida-vuelta de los cuerpos-internet (Soulages, 2014). El espacio convirtiéndose en su objeto. Sin embargo, a menudo, se desplazan o son desplazados por una necesidad evidente, por razones históricas y geopolíticas, deportación, exilio, desplazamiento, éxodo, nomadización, desterritorialización, etc... Hijas e hijos de su tiempo, se encuentran, como tantos otros, obligados a partir, obligados a llegar, obligados a huir, obligados a pasar: paseantes como paseadores10 yendo y volviendo.

Para pensar sus obras, es necesario hacer sus historias, mejor aún, la historia de sus historias.

"Ignorar la historia de esa historia, afirman con lucidez Furet y Ozouf, sería borrar los paisajes intelectuales que lo atraviesan, desconocer la sedimentación de esos problemas"11, en efecto, se trata de los problemas del idavuelta que se cuestionan a veces los historiadores, que posiblemente dependan más de sus trayectos que de la tradición histórica que, en la búsqueda de sus pensamientos, condiciona sus posibles representaciones. Hacer la historia es, a la vez, aspirar a una realidad y producir el marco artificial para esas potenciales y futuras representaciones. Las reflexiones epistemológicas de Bachelard sobre la psiquis son mutatis-mutandis (cambiando lo que se daba cambiar), totalmente aplicables para la historia (del arte) que, con demasiada frecuencia, quedan por hacerse.

\section{Ulises o el difícil regreso}

\section{El ida-vuelta de un artista contemporáneo}

Para comprender la problemática de las mujeres y de los hombres seducidos por el idavuelta, y muy en particular de los artistas sudamericanos, tenemos que retroceder y realizar un largo rodeo. Estudiemos pues a un héroe fundador, Ulises.

Ulises no es artista, o más bien sí: es artista de su propia vida; su propia vida se convirtió en su obra; un artistacontemporáneo12 pues. No hace de su vida una estatua inmóvil, se trata de una performance que juega con la movilidad, las idas, los rodeos y los regresos. Muchos artistas contemporáneos de la movilidad podrían tomarlo como modelo; ¿podrán un día llegar a la estatura de este héroe?

Para empezar, Ulises es un rey, el rey de Ítaca. Su renombre es por su mètis (destreza). ¿Cómo traducir mètis? Por “¿inteligencia astuta?" Pero ¿no será peyorativo e insuficiente?

Un hombre astuto es, para nosotros hoy, un hombre algo falso, engañoso, zorro. De hecho, Ulises es astuto, puesto que es marinero, puesto que es mediterráneo. El mediterráneo no es un campesino inmóvil anclado en su tierra, como un árbol -“Este árbol era un centinela, la única persona que velaba por él”. Escribe Patrick Modiano; es un marinero móvil quien ha echado el ancla surcando los mares, a su gusto, abandonándose en ellos, sueña

con ir a otra parte. El campesino calcula, hace previsiones, planifica: es un matemático; los Egipcios son el mejor ejemplo, ya que dieron origen de la geometría, nos ha contado Husserl; esta ciencia les enseñó que, la movilidad aparente del Nilo y de sus crecidas -el ir y venir natural-, la inmovilidad existente: la figura geométrica -objeto de pensamiento por excelencia- permitía encontrar de nuevo el campo para el cultivo -objeto concreto por excelencia; eran pitagóricos sin saberlo, abiertos al orfismo; partiendo de ellos, racionalismo y misticismo podían desarrollarse, mathesis universalis y mystica universalis también.

Pero la movilidad del Mediterráneo, sus idas y vueltas no son como los del Nilo: Ulises el marinero es empirista y pragmático, no puede predecir el tiempo que hará en unas cuantas horas, mientras un campesino piensa en veinte años y Colbert pensaba en cien años -Colbert hacía que plantaran castaños en los bosques de Tronçais para que la Marina francesa, un siglo más tarde, pudiera poseer los mástiles sólidos del mundo y Nostradamus preveía el porvenir. Estas diferencias radicales en cuanto a la temporalidad explican las diferencias radicales en cuanto a la movilidad: el tiempo modifica el espacio de la movilidad.

Ulises debe hacerse con el kairos (momento), la ocasión, y, como lo decía Revault d'Allones para caracterizar al artista, hacer todo para lograr el objetivo. La mètis (destreza) de Ulises es que su inteligencia superior lo guía a adaptarse a la situación; es indispensable para la pesca, la caza, la equitación, para todo lo que pertenece a lo imprevisible, de la naturaleza y de la vida. Apunta a ganar no tanto tomando el camino más directo, el más corto para alcanzar el blanco, pero inventando un camino indirecto: solo en geometría la línea recta es el camino más corto entre dos puntos; pero vivimos en un espacio que no es geométrico, sino geopolítico, incluso geoartístico y geofísico. Ulises inventa nuevas mediaciones; la movilidad es su naturaleza; está en movimiento en un mundo en movimiento: está vivo. Vivo y sobreviviente gracias a la movilidad: en contra de las tempestades, en contra de 
los pretendientes de Penélope. Gracias a su mètis fue un soldado temible, un jefe de guerra apreciado en la guerra de Troya.

\section{El ida y vuelta de una geopolítica}

En el siglo pasado, otro Ulises salvó Francia, a través del ida-vuelta de Francia-Inglaterra- Francia, geopolítica por excelencia: el general De Gaulle. Hombre de la movilidad, lo es por tres razones: para empezar, con relación a su origen, el ejército, es móvil porque piensa y pone en tela de juicio sus principios mismos, lo que puede producir problemas en ese cuerpo en el que la disciplina es la fuerza de los ejércitos y el pensamiento del principio de la desobediencia es condenado a muerte por rebeldía. De Gaulle es móvil, puesto que es sujeto, un pensador, un rebelde, un sujeto móvil que tiene un motivo. Hombre de la movilidad, lo es también cuando preconiza la guerra de movimiento en contraposición a la guerra de trincheras, el tanque contra la línea Maginot, la guerra del futuro contra la guerra del pasado (14-18), la adaptación, la anticipación y la invención contra la repetición, el estancamiento y la institución. Hombre de la movilidad, lo vive cuando se instala en Londres por Francia, cuando apuesta por la Francia de África y del Mediterráneo para vencer al ejército alemán, cuando retoma la noción de capital móvil de un país pensado por Juana de Arco. Encarna el ir-volver, París-LondresParís, pero Francia es él mismo cuando está en Londres; no es de extrañar si este inmigrante preocupaba a Roosevelt quien, fue y vino USA-Europa-USA...

Más que un comportamiento, la movilidad desvela una naturaleza; los aficionados al futbol lo saben muy bien al comparar la movilidad brasileña -el baile futbolístico- con la rigidez del equipo alemán. La samba no es un baile militar. Pollock no es Mondrian. Mozart no es Bach. René Char no es Paul Valéry: ¿será por eso que fue jefe de guerra y resistente, así como el gran especialista de la mètis (destreza) Jean Pierre Vernant?

Ida-vuelta - Estética de la movilidad

Hombre de movilidad, Ulises es pues polutropos, "Ulises, el de los mil caminos", es decir mil astucias; supera en ingenuidad a todos los demás héroes: su prudencia y su astucia -sus disfraces y sus mentiras- le salvan la vida en varios momentos durante todo su periplo por el Mediterráneo. Los hombres de movilidad del Mediterráneo deben seguir su ejemplo.

Y el reino de Ulises no es un territorio unido cercado por muros y fronteras, así como se construyen hoy en el Mediterráneo13, pero, como nos lo repite constantemente Homero, es un archipiélago compuesto por cuatro islas -Ítaca, Duliquio, Léucade y Zakynthos. Para vivir su reino, la movilidad es una obligación para Ulises; pues, todo trayecto por mar es una aventura, cuando además, no existen fronteras fijas como murallas o muros; es un reino abierto a los cuatro vientos, abierto a los cuatro mares. El pensamiento entonces es una aventura de la movilidad, pensamiento en archipiélago, lazo entre islas: la inteligencia es cuando se enlazan cosas juntas. No solo una isla puede generar un espacio y un espíritu de concentración totalitario, como la de W de Pérec, sino cuatro islas -una pluralidad, un archipiélago de la movilidad- desarrollan una movilidad y agilidad del espíritu, éste está

confrontado a la alteridad compleja: no nos podemos refugiar tras unas murallas, como un niño bajo las faldas de su madre. Ulises afirma incluso que posee una multitud de islas e islotes, como Arkoudi, Meganisi, Oxia, las Echinades.

Y Ulises deja Ítaca para luchar en la guerra, a pesar de la profecía según la cual su regreso sería peligroso. La movilidad es siempre un riesgo, la vuelta también: vivir es un riesgo, uno puede morir, se puede morir por ello. Pero la alternativa no está abierta, porque la movilidad es la reiteración y, como nos lo enseñó Freud, la reiteración es la muerte; tremenda verdad para el artista que muere reiterando su propio estilo, para el hombre que deja su país de origen y reitera en otro lugar lo que creía ser en el país, incluso reitera su sufrimiento sin poder superarlo o hacer algo con ello.

Ulises lo sabía quizás, él quien, según otras versiones, simula la locura para no ir a la guerra: siembra sal y piedras en el campo que labra. Siempre es tan difícil ser móvil como a veces ir a la guerra y arriesgarse, no sólo a combatir, sino a morir y a perder a los suyos

-Penélope y Telemaco. Irá pues a la guerra y, por supuesto, se encargará de la movilidad, es decir, embajadas; acude a Troya para negociar el regreso de Helena.

Y cuando la guerra acaba, no vuelve, no hay regreso, aparentemente se trata de una simple ida; hoy, para algunos, así es: cuando los estudios acaban, no vuelven. Ulises vaga por los mares: comparar con Errance (Vagabundeo) de Raymond Depardon, campesino hoy fotógrafo y reportero, por lo tanto marinero, por lo tanto Ulises; pero vuelve un día a la granja de sus padres. Y encuentra a las sirenas, la música y las mujeres, el arte y la sexualidad: no puede quedarse inmóvil. Y cuando la ninfa Calypso quien lo mantiene en su isla durante siete años le ofrece la inmortalidad, no elige esa forma de inmortalidad. Mejor aún, acude al país de los Cimerios, es decir a los Infiernos, aquel reino de Hades, donde encuentra las sombras errantes de los héroes -versión extraña del vagabundeo en el mar:

"Pero, ante todo, emprender otro viaje Hacia las casas de las Hades y de la gran Perséfone"14 
Pero, veinte años después, vuelve a su casa, disfrazado de mendigo: es la vuelta.

El ida-vuelta se ha realizado.

¿Pero, quién podía reconocerlo tras un viaje tan largo? Mendiga el reconocimiento: de su mujer y de su hijo.

¿No es lo que mendiga el artista o el inmigrado cuando vuelve, muy temeroso que nadie sea profeta en su país? ¿Qué país?

\section{Descentramiento geoestético}

Ulises es un héroe: nos inspira. Es un héroe que descentra el relato: del hombre pasamos al viaje y del viaje al espacio geopolítico y geoartístico del viaje: el Mediterráneo. Fernand Braudel vivió ese descentramiento cuando pasó de un proyecto de tesis sobre Felipe II y el Mediterráneo a una tesis sobre el mediterráneo de Felipe II: El Mediterráneo es el corazón, es lo que une y opone a los países y a los hombres; la movilidad de los hombres, las ideas y las cosas son la modalidad principal en tanto modo de realización: uno puede estar fijo sobre la tierra, es más difícil en el mar y prácticamente imposible en el aire. Y por ello Ulises es el héroe paradigmático de la movilidad mediterránea.

Y cuando Dante evoca en el Canto XXVI del Infierno en la Divina Comedia, Ulises se había ido de nuevo de viaje, dependiente de la movilidad y de la curiosidad. Viajar es querer conocer otras cosas y más cosas aún, verdadera libido sciendi, culpable de un Dante cristiano.

Además, todo viaje -los egipcios nos lo enseñaron- es un viaje hacia la muerte.

Y cuando Joyce publica en 1922 una de las novelas más importantes del siglo XX, Ulises, realiza una reinterpretación dual de La Odisea: el artista actúa entonces en el papel de Telémaco. Joyce cumple con esta novela una revolución radical, la movilidad no es ya geográfica, sino geoartística. Lo que no impide al autor crear una movilidad espacial yendo a vivir, por ejemplo, a Francia. Sin embargo, estas movilidades están

acompañadas por una movilidad lingüística: para empezar con la novela Finnegans wake y el desplazamiento en el interior de ella hacia una pluralidad de lenguas; luego, con ese otro irlandés que fue a vivir a Francia y es uno de los discípulos de Joyce -Samuel Beckett-, el trabajo sobre dos lenguas y sobre la traducción que permite viajar de una lengua a otra, de una orilla a la otra. Y sabemos que el problema de la lengua juega un papel fundamental para los hombres y los artistas quienes se aventuran a esta movilidad mediterránea: movilidad de cada lengua, movilidad del sujeto de una lengua a otra (Soulages, 2015). Una nueva geoestética iniciada por Joyce. Realizar una obra, es fabricar una lengua propia que un día tal vez hablarán otros: movilidad futura. Homero logró esta hazaña.

\section{Du Bellay o el regreso necesario}

\section{El retorno de Ulises}

Pero el ida-vuelta y la movilidad son acompañados siempre, en un momento o en otro, del deseo de inmovilidad, del deseo de suspensión de esta movilidad, de esta suspensión se mantenga en suspenso: pasamos de la hazaña a la estatua, del cine -arte del movimiento- a la fotografía -arte de la imagen fija-, del jadeo a la lactancia, del don de las lenguas a la lengua materna.

Se desea la vuelta.

Se quiere volver al punto de origen: ¿vivir en casa? Quizás. ¿Morir en casa? Seguro. O bien volver quizás para volver a partir, no quedarse, no realizar fijaciones, no ser arcaico -entonces ser arqueólogo para no ser arcaico: vean la obra de Sandro Oramas.

Joachim Du Bellay plantea el problema en 1558 en su obra Les Regrets (Las añoranzas) y muy particularmente en el soneto XXXI "Felices quienes, como Ulises...". Él, el poeta francés, fue a Roma, porque un viaje era un sueño y una iniciación necesaria para cualquier humanista, hace quinientos años: esta movilidad lo alimentó, lo formó, lo hizo artista gracias a la geoartística. Sin embargo, escribe Les Regrets: al hombre de la movilidad siempre le invade, en cierto momento, las añoranzas que lo constituyen: ¿tendría que haber ido por allí, el Mar o el Océano, elegir ser un ser móvil, pero, de facto, en alguna parte errante, como un perro errante, sin domicilio fijo, sin domus, sin casa donde vivir, dónde habitar -habría dicho Heidegger-, mejor aún, dónde estar? Y estas añoranzas también se realizan en la movilidad en el seno del arte: ¿hice bien pasando de tal práctica artística a tal otra, abandonando las artes de mi domus para abrazar las de otros países? ¿He sido yo-mismo o he estado bajo influencia -de la domus para empezar, luego de otros lugares?

¿He sido fiel o traidor? Hasta tal punto, para algunos, la expresión "arte contemporáneo" es sinónimo de "neocolonialismo": lo comunal prohíbe entonces el universalismo a la que aspiraba Okwui Enwezor y descalifica la movilidad.

¿Y si un hombre, un artista no se definiera por su presente o pasado, por su devenir, por su camino recorrido, por su movilidad? Algunos piensan que por su ir-volver.

El retorno de Joachim

En una decena de sonetos de los Regrets lo que domina es, precisamente, el motivo del viaje desdichado: periplos ejemplares que toma como metáforas de lo suyo, Du Bellay solo mantiene los obstáculos y el deseo nostálgico, melancólico, del regreso. 
"Felices quienes, como Ulises, han realizado un bello viaje

O como aquél quien conquistó el toisón, vellón

Y luego volvió, lleno de saber y de razón,

¡Vivir entre sus padres el resto de su vida!"

La felicidad es anunciada enseguida: Du Bellay no está desesperado. Ni lleno de violencia y de odio, como pueden estar invadidos algunos seres víctimas de una movilidad -a veces, pero no siempre, obligada- durante el cual su sueño y su ilusión fracasaron por la realidad. Feliz pues, pero ni de la movilidad, ni del trayecto, ni del puerto de llegada, sino del regreso. Provocación del poeta que piensa contra la doxa habitual sobre la movilidad exaltante que hace de un simple mortal un héroe; por lo tanto, paradoja, reflexión pues y no reiteración. ¿Sin embargo, la felicidad de Ulises o de Jasón sería tan grande sin la movilidad, sin lo que reconoce ser "un bello viaje", sin este aprendizaje y esta experiencia enriquecedores? Para Du Bellay, la movilidad del artista y del hombre es un medio, no un fin, una iniciación, una educación para vivir y crear después.

Pero parece ir más lejos aún: el niño vuelve con sus padres; el poeta no dice que le toca fundar una familia: su descripción es incluso algo asfixiante: ¡Vivir con sus padres el resto de su vida! ¡Cuánta prisión! ¡Qué asfixia! Familia, os odio, escribía Gide. Es, igualmente, lo que dice un día el marinero, el hombre de la movilidad. Pero la nostalgia está en este punto: Du Bellay desea volver a su pobre y pequeño local y no quedar en lo global romano: pretende volver a ser un niño y volver a encontrar las "ventajas" secundarias y colaterales. El regreso, es el regreso a la infancia, a una infancia, al menos en su tentativa.

“iCuándo volveré a ver, desgraciadamente, mi pueblecito

Humear la chimenea, y en qué estación

Volveré al cerco de mi pobre casa,

Que es para mí una provincia, y mucho más!"

Los lugares contemporáneos del ida-vuelta

Las interrogaciones del ida-vuelta

¿Y si algunos creadores de imágenes, artistas y pensadores pudieran ayudar a interrogar mejor la localización contemporánea? ¿Y si la localización artística contemporánea fuese una suspensión de la huida, de su propia huida, con el fin de pasar una temporada en suspenso o en el flujo de la obra, en los objetos, las imágenes y los procesos? ¡Y si el lugar fuese un lugar determinado? ¿Y si la localización fuese ante todo lenguaje? ¿Y cómo habitar un lugar determinado contemporáneo? ¿Y quién dice el lugar? ¿Y qué dice el lugar? ¿El genio del lugar? ¿El Dios Lares? Cada viajero, cada migrante es un Etrusco venerando, en un momento dado, a su Señor. ¿Y si la localización contemporánea fuese, a la vez, un tema para artistas y pensadores contemporáneos, una moda para los sujetos ingenuos del GPS y una medida peligrosa creada por una sociedad no sólo de control, sino también de localización de los sujetos?

¿Y si olvidáramos el sentido del regreso como una prueba encarnada, en un Ulises o en un Du Bellay? ¿Y si el sujeto consumidor anticipara, de facto, la localización del Leviatán político, económico e ideológico?

¿Y si la localización contemporánea fuese sin embargo una necesidad radical para cada ser? ¿Y si fuese un derecho del hombre frente a las deslocalizaciones étnicas, políticas y económicas y a los desplazamientos ordinarios y obligados, en la sociedad contemporánea de desplazamiento más que de reparto? ¿Un derecho a volver? ¿Y si la localización contemporánea debiera ser articulada con el nomadismo, con la desterritorialización, con la deriva y con el vagabundeo? ¿Y si, en época del flujo, del fluir y de lo viral, fuese un eco de la búsqueda por un punto fijo del siglo XVII?

Más me gusta la estancia que construyeron mis antepasados

Que aquellos palacios romanos el frente audaz,

Más que el mármol duro me gusta la pizarra fina,

Más aún mi Loira galo que el Tigre latín,

Más mi pequeño Liré que el monte Palatino,

Y más que el aire marino la dulzura angelical.

¿Y si la localización contemporánea permitiera acabar con la locura de la grandeza y actuar a un nivel minúsculo, pero efectivo? ¿Y si ella fuese una condición necesaria para una ética posible? ¿Y si ella obligase a reinterpretar lo contemporáneo Small is beautifull y el antiguo De entre las cosas, algunas dependen de nosotros, las otras no dependen de Epicteto?

¿Y si la localización contemporánea debiera ser también la apertura a la humanidad en su universalidad y el rechazo a lo comunal tribal y gregario? ¿Y si la localización contemporánea fuera la condición de posibilidad de una mundialización positiva, particularizante y enriquecedora, a diferencia de la globalización negativa, uniformante y alienante? ¿Y si ella permitiera pasar de lo universal abstracto a lo universal concreto? ¿Y si la localización contemporánea fuera el correlato de una sensibilidad contemporánea centrada en la intersubjetividad y el reconocimiento de la alteridad? ¿Y si la localización contemporánea fuese necesaria 
epistemológicamente no solo para saber desde dónde hablamos y desde qué región de lo real se interroga, sino sobre todo para comprender las marcas, las señales y las demarcaciones de los demás -especialistas ciertamente-, pero sobre todo mujeres y hombres de esta localización particular? ¿Y si la localización nos confronta con un Es gibt15 epistémico, ético y estético ineludible, no sólo para tenerse en cuenta, sino, sobre todo, para ser un punto de partida de la reflexión? ¿Y si esta transmisión debiese ser una condición de la creación? ¿Y si la primera etapa de pensar, de imaginar y de crear, consistiese ante todo en construir de otra manera un lugar nuevo?

\section{El horizonte del ida-vuelta}

Entonces, el hombre de la movilidad y del regreso sería feliz, habría una movilidad feliz y un regreso feliz. Un archipiélago de felicidad...

¿Se trata de un sueño o de un pensamiento? Un horizonte.

Escuchemos a Modiano:

Mejor valía saber más. Al menos, con la duda, todavía queda una forma de esperanza, una línea de fuga en el horizonte. Uno piensa que a lo mejor el tiempo no terminó su trabajo de destrucción y que todavía habrá encuentros. (Modiano, 2010, p. 143).

¿Tiene el ida-vuelta un horizonte, un principio, un adiós? Puede y no puede ser, pero en todo caso, se resguarda, huye: Modiano o la estética de la huida, estética del punto de fuga, o bien: de la fuga? ¿Modiano y Bach?

En el fondo, se trata para un novelista, de arrastrar a todos los personajes, los paisajes, las calles que vió a una partitura musical donde se repiten los mismos fragmentos melódicos de un libro a otro. Pero una partitura musical que parecerá imperfecta. Hay en el novelista la pena de no haber podido ser músico. (Modiano, 2013, pp. 9-10)

Modiano o el imposible regreso creador

Modiano y los otros

Toda la obra de Modiano es un intento por volver a su pasado e intentar comprender, como si, de ese pasado, se hubiera ido y quisiera volver, como si fuera un emigrante del pasado transformado en un inmigrante del presente y quisiera ir-volver. Pero no puede encontrar su pasado, así como el migrante no vuelve a encontrar su país de origen: el origen del mundo es imposible de ver; es imposible tal como sucede con lo real, a partir también del cuadro de Courbet que fuera escondido-velado por Lacan cuando se encontraba en su posesión.

Pero esos imposibles reencuentros con el pasado los volvemos a encontrar en el argentino Erbetta que vive en Francia o en Koest, el argentonés que vive en Provenza, el escritor produce una obra, así como Erbetta con sus fotos de archivos y Koest con sus fotos de familia.

El ida-vuelta como pasado-presente-pasado es imposible en el sentido en que el pasado está superado y metamorfoseado, así como los lugares se transforman; por lo tanto, es el momento de la creación artística. De allí la estética del ida-vuelta.

Examinemos lo dicho en diferentes novelas de Modiano.

\section{Comentario}

La vuelta al pasado es una vuelta a un mundo de sombras, de siluetas y de fantasmas.

¿Cómo puede captarse algo sobrecogedor? Es por lo que el autor comienza su novela con la frase de Dylan Thomas como epitafio. ¿Quién eres, tú, mirón de sombras?" (Modiano, 1980, p. 9). El tema refleja el problema del misterio, del regreso y del pasado en el misterio de la persona ¿quién eres? Además indica la arrogancia del que quiere ver las sombras: solo ve sombras y no la realidad y, además, ¿quién es para pretender querer conocer estas sombras y este pasado? El pasado nos es rechazado, no tiene retorno.

Entonces el sujeto solo se encuentra ante un mundo indefinido y flotando: "Cuando pretende encerrarse en sí mismo, sus ojos se empañan y el mundo exterior no es más que una masa indefinida. Conozco muy bien este proceso puesto que lo empleo a menudo" (ibid, p. 42). Es a su vez el narrador y el escritor quienes emplean esta técnica: la puesta en indefinición del mundo; es lo que oscurece su misterio; y es lo que otorga su fuerza narrativa

y ficcional que hace que trabaje el imaginario del lector que se transforma entonces, él también, en un mirón de sombras. El novelista ha tomado en sus redes al lector; lo ha conseguido; ¿este último está pillado por esta búsqueda-regreso del pasado de otro individuo -el narrador? No se sabe... Y es porque no se sabe que se continúa leyendo, se quiere saber, se interpreta y se proyecta en ese relato de principio singular: este regreso deviene en el regreso, el de Ulises, de Du Bellay, de Erbetta, de Koest, el nuestro.

El narrador encuentra numerosos obstáculos, pero, como un caballero de la Mesa redonda, cree que encontrará un día el grial, es decir, el camino hacia el pasado, el camino de regreso: "Me ha contestado de manera muy 
vaga diciéndome que había sido educada en el extranjero. No insistí. Con el tiempo, pensaba, acabaré sabiéndolo todo" (ibid, p. 67).

Pero, así como canta Ferré, "con el tiempo se va, todo termina yéndose", y el narrador no sabrá jamás. Todo se desvanece, ninguna prueba resiste; en el mejor de los casos, se da cuenta que no sabrá:

“¿En qué época? Durante los años treinta, creo. ¿A qué número? Lo ignoro.”(Modiano, 2013, p. 224) Incluso la existencia posible de alguien se torna problemática: "He querido saber más, pero no encontré la menor huella, la menor prueba del paso de James Levy en la tierra" (ibid, p. 225). La realidad se hace igualmente improbable:

"Un espejismo sin duda.

Por otra parte, todo era espejismo, todo se encontraba desprovisto de la menor realidad en este país" (ibid, p. 289). El hombre desaparece, como en las últimas líneas de Las palabras y las cosas: "el hombre se desvanecerá, como las orillas del mar en un rostro de arena” (Foucault, 1966, p. 398). Pero aquí, ya no es su figura histórica la que desaparece, sino un hombre de carne y hueso, como los rostros de Fautrier al final de la Guerra: "Un vaho en

forma humana, un salvavida que iba a desaparecer de un momento a otro" (Modiano, 2013, p. 313).

Tan sacudidos, tan inciertos por lo que debo esforzarme mucho para encontrar algunas huellas y algunas balizas en esta arena movediza como cuando uno se esfuerza en rellenar con letras medio borradas un impreso del estado civil o una encuesta administrativa. (ibid. p. 831)

Porque todo flota, como lo pensaba Heráclito, pero hasta el punto de impedir cualquier reconocimiento: "Siempre vestido con trajes claros. Así flotaba en mi recuerdo de niñez" (ibid, p. 205). La memoria es flotante, más o menos como la atención flotante de la cual habla el psicoanálisis, puesto que, a diferencia de esta última, no descubre nada. "Todo flotaba, en Lausanne, la mirada y el corazón se deslizaban sin poder agarrarse de ninguna aspereza. Todo era neutro. Ni el tiempo, ni el sufrimiento habían depositado su lepra aquí.

Por otra parte, desde hace varios siglos, en este lado del Leman, el tiempo se había detenido" (ibid. p. 272): ningún punto fijo puede encontrarse, que, como el de Arquímedes, de Descartes, de Pascal o de Leibniz, permitiría al sujeto fijarse para encontrar poco a poco el pasado, la red del pasado; nada, nada se encuentra de forma inconfundible. El universo de Modiano es una mezcla de precisiones inútiles y de indefiniciones devastadoras, como un mundo visto por un psicótico que atraparía todos los detalles, pero no la totalidad, aún menos el sentido de esta totalidad: “¿por qué siempre tengo recuerdos tan precisos e inútiles?" (ibid, p. 300)

\section{Cómo callar}

¿Pero no es mejor callarse, en un momento dado, callarse ante una obra que interroga al ida-vuelta y simplemente escucharlo? No realizar más un ir-volver desde ella a nosotros, y recibirla como un don, nosotros que le somos extranjeros.

Puesto que una obra magna nos enseña que debemos respetarla, respetar sus fronteras que la mantienen en su pureza -Beckett y el respeto a los titulares...-, hacer que seamos un extranjero interesado, el que escucha una lengua que no siempre entiende.

A su vez el regreso hacia imposible el reconocimiento del País Natal: ¿pero cuál es?

Estás aquí porque has querido recorrer una última vez los años para intentar comprender. Es aquí, bajo la luz eléctrica, Place Blanche, cuando todo empezó. Una última vez, has vuelto a tu país natal, en el punto de partida, para saber que había que tomar un camino diferente y si las cosas hubieran podido ser de otra manera. (Modiano, 2001, p. 147)

"Pasados unos minutos no había reconocido nada como si estuviera preso de amnesia y no era más que un extranjero en su propia ciudad". (Modiano, 2014, p. 129)

El regreso apunta lo que precede al nacimiento: ¿por ello parece imposible?

No tenía más que veinte años, pero mi memoria precedía mi nacimiento.

Estaba seguro, por ejemplo, haber vivido en el París de la ocupación puesto que recordaba algunos personajes de esta época y detalles ínfimos y turbadores, de los que ningún libro de historia menciona. Sin embargo, intentaba luchar contra la gravedad que me tiraba hacia atrás y soñaba en liberarme de una memoria envenenada. Hubiera dado lo que hiciera falta para ser un amnésico. (Modiano, 2013, p. 271)

"Recuerdo todo. Quito los carteles pegados por capas sucesivas desde hace cincuenta años para encontrar de nuevo pedazos más antiguos. Pasábamos ante lo que fue Winter-Palace y he visto jóvenes inglesas y jóvenes rusos enfermos de mil novecientos diez". (ibid, p. 333)

"Pero aunque quisiera reunir recuerdos mucho más recientes, pertenecen a una vida anterior que no estoy muy seguro de haber vivido". (Modiano, 2010, p. 148)

El olvido prohíbe la memoria: ¿el ir prohíbe el volver? 
"No quedaba nada de aquellos años". (ibid, p. 158)

"Quince años pasaron de nuevo en una neblina tal que se confundían los unos con los otros”. (ibid, p. 180)

El regreso imposible sumerge al otro al anonimato; ¿pero cómo hacer frente a este imposible regreso del nombre?

"Son personajes quienes dejan pocas huellas tras de sí. Casi anónimos". (Modiano, 2013, p. 658)

“Creo que permanecerá siempre anónimo, ella y las demás sombras paradas aquella noche”.(ibid, p. 681)

El regreso de los padres es incluso imposible: ¿qué queda de lo aparentemente real?

"Apenas si recuerdo más detalles de aquel periodo de mi vida. Casi olvidé los rostros de mis padres". (Modiano 2010, p. 16)

"Incluso las fotos de mis padres se han transformado en fotos de personajes imaginarios. Únicamente mi hermano, mi mujer y mis hijas son reales". (Modiano, 2013, pp. 9-10)

La estética \& lo existencial

La huella

Así una estética de ida-vuelta no es una estética del triunfo, sino la de un enigma, del misterio y de la duda; es por lo que es existencial: se encuentra frente a marcas, huellas, sombras de sombras; incluso, hasta cuando se apoya en la fotografía (Koest, Erbetta, Modiano).

Porque una foto es una huella, ¿pero una huella de qué?

¿Una huella de lo que se ha querido fotografiar o bien de lo que fue fotografiado sin premeditación, sin voluntad, sin deseo? ¿Una huella del objeto en sí o bien de un simple fenómeno? ¿Una huella de lo fotografiable o bien de lo que no lo es?

¿Pero por qué no igualmente una huella del sujeto fotografiando o del acto fotográfico16, de la acción fotográfica o de lo metafotográfico? ¿Una huella del punto de vista o del enfoque?

¿Una huella por haber obtenido el negativo o de la matriz numérica o bien de su explotación?

¿Y por qué no una huella del material fotográfico particular o bien de las condiciones epistémicas y técnicas en general que han posibilitado esta foto particular?

¿O por qué no una huella del pasado? ¿Pero de qué pasado? ¿El del objeto a fotografiar o el de la foto? ¿El del sujeto fotografiando, el del sujeto fotografiado o bien el del sujeto quien mira la fotografía? ¿Pasado del tiempo o bien del espacio? ¿Pasado de la vida o bien de la muerte? ¿Una huella de todo esto a la vez? ¿Puede ser. Pero cómo?

La fotografía crea problema.

El a la vez -ida-vuelta

Es quizás porque crea problema -en cuanto a la teoría general que podríamos desarrollar y en cuanto a la aproximación particular a partir de la foto entregada- por lo que hace soñar, cuando trabaja nuestra ensoñación y nuestro inconsciente, cuando habita nuestra imaginación y nuestro imaginario y cuando se encuentra en el continuum de lo visible, un agujero negro brillante que nos hace cambiar a otro espacio y en otro tiempo y que, a veces nos confronta con la alteridad -¿pero qué alteridad?-y a veces nos regresa a nuestro yo - ¿pero qué yo? Toda foto es una imagen rebelde y deslumbrante que permite interrogar a la vez sobre el ir y el volver, lo de más allá y lo de acá, el pasado y el presente, el ser y el futuro, la fijeza y el flujo, lo continuo y lo discontinuo, el objeto y el sujeto, la forma y el material, el signo y... la imagen. Y eso es verdad, pero según modalidades diferentes, tanto

para una foto sin-arte17 como para una foto que pertenece a una obra fotográfica y que traslada, la mayor parte del tiempo, al trabajo de un artista y, a menudo, al de un poeta.

"Un poeta, escribe René Char, debe dejar huellas de su paso, no pruebas, Solo las huellas hacen soñar"18. ¿Quién puede creer aún que la foto es una prueba? Una foto es una huella, es por lo que es poética. El fotógrafo es el que debe dejar, mejor aún, quien debe crear huellas de su paso y del paso de los fenómenos, de las huellas de su encuentro -fotográfico- con los fenómenos. Es por lo que es artista.

\section{El Resto}

Toda foto es pues una huella enigmática que hace soñar y que crea problemas, que fascina y que inquieta. Por un lado, queremos creer que mediante ella, el objeto, el sujeto, el acto, el pasado, el instante, etc. van a ser reencontrados; por otro, debemos saber que no los devuelve nunca: al contrario, es la prueba de su pérdida y de su misterio; más aún, los metamorfosea. Esta ilusión de los reencuentros y esta imposición de la pérdida 
alimentan la práctica fotográfica -el hecho de hacerlas y el de verlas. Este problema y este misterio convocan al artista a explorarlas y al filósofo a pensarlas: la estética de la fotografía ¿sería pues una estética de lo que queda luego de la pérdida?

"De ellos no queda más que los nombres". (Modiano, 2013, p. 831)

"Ya no quedan todos aquellos gritos de sufrimiento y todos los rostros horrorizados del pasado como de las llamadas cada vez más sordas, con contornos indecisos". (ibid, p. 289)

En todo caso, la fotografía es una ocasión para el poeta, una suerte para el artista, un privilegio para el hombre en general. Las obras fotográficas, por su belleza y su carácter sublime, han demostrado que el arte fotográfico existe; es pues una necesidad para el filósofo de confrontar un día con él, puesto que estos retos son fundamentales: son existenciales, estéticos y epistemológicos. Los desafíos de la fotografía corresponden a la filosofía en general -son, por ejemplo, lo real y sus representaciones, el sujeto y el objeto, el ser y el tiempo, la vida y la muerte- y de lo estético en particular -por ejemplo, el arte y el sin-arte, la creación y la técnica, el fragmento y la obra, el arte fotográfico y las demás artes, el ir y el volver. Una reflexión filosófica permite así interrogar no solo la fotografía y el arte, sino también las relaciones de los hombres con el mundo, con las representaciones y con ellos mismos.

\section{La pérdida y el resto}

La fotografía es pues la articulación de la pérdida y del resto puesto que refiere al idavuelta, a la emigracióninmigración y a la frontera de aquellos dos países que separa y une.

Pérdida de las circunstancias únicas a causa del acto fotográfico, del momento de ese acto, del objeto a fotografiar y de la obtención generalizada irreversible del negativo o de la matriz numérica, en definitiva del tiempo y del ser pasados. Resto constituido por aquellas fotos que se pueden realizar a partir del negativo. La pérdida es irremediable: la fotografía nos lo grita, nos lo muestra, nos lo hace imaginar; si la pérdida es absoluta y violenta, no es porque el tiempo, el objeto o el ser perdidos tenían anteriormente un gran valor para nosotros o en sí, sino porque ese tiempo, ese objeto o ese ser están ahora y para siempre perdidos: ¿es porque están perdidos que, de repente, su valor se hace absoluto y que, en seguida, este absoluto alcanza y contamina la pérdida, nuestra pérdida. El resto no puede ser un remedio milagroso, salvo para aquellos que necesitan creer en los milagros; de hecho, nos alivia la pérdida, nos permite realizar un funeral? A veces, quizás; en todo caso, es la

única cosa que nos queda, con lo que tendremos que pelearnos, debatirnos, combatirnos, por lo que el artista podrá realizar la obra: la fotografía o el arte de acomodar los restos...

Pérdidas infinitas, restos infinitos...

En cuanto a la escena que muestra lo irrevelable el fotógrafo se enfrenta con el objeto a fotografiar que no es medible ni conocible salvo por su visibilidad fenoménica. Por revelar lo inacabado afronta en el negativo o en la matriz numérica que son medibles y manipulables como un instrumento. Parte en el primer caso de este objeto para hacer un negativo o una matriz numérica y, en el segundo caso, del negativo o de su matriz numérica para hacer una fotografía. En el primer caso, puede realizar varios negativos o matrices, pero no son nunca exactamente los mismos, tomando en cuenta el tiempo y lo irreversible; una vez que el procedimiento se inicia desde la exposición hasta el secado, para el negativo-, el proceso terminará irremediablemente, no podrá jamás volver al mismo punto de partida; es por esto que el proceso tiene un fin en donde comienza otro, la de la película

expuesta, de la matriz constituida hasta la foto realizada: esta problemática y esta práctica han sido tenidas en cuenta por Denis Roche y Opalka. Por lo contrario, en el segundo caso, es lo inverso lo que se produce: puede teóricamente rehacer la misma foto, pero no es eso lo que le interesa personalmente puesto que no es una máquina; el trabajo del negativo o de la matriz le lleva a realizar fotos diferentes, pero nunca culmina haciendo algo diferente; su tarea es inacabable; luchará pues contra este inacabable y quizás, en un momento dado, decretará que ha acabado, y que de este negativo o de esta matriz no hará más fotos, que seleccionó y creó la que quería, pero sabe que su decreto no es jamás definitivo: él u otro podrán siempre explorar de nuevo el negativo o la matriz, hacer otras fotos; como mucho, un artista podría constituir toda la obra de su vida en la exploración indefinida de un único e igual negativo que incluso no hubiera realizado.

Así, en las dos prácticas habitan compromisos opuestos: una lucha en contra del flujo del tiempo, otra en contra del regreso eterno, esta no podrá realizar nunca la misma cosa, a pesar de los deseos y toda la voluntad, aquella puede seguir haciendo la misma cosa, pero se la insta por la especificidad del trabajo del negativo a realizar de forma diferente.

Un ida-vuelta sin fin.

Con un año y medio, W. Ernest Freud juega con una bobina atada a un hilo: lo lanza lejos, y la atrae hacia él, luego la envía de nuevo, y la recupera de nuevo, repitiendo "Fort / Da" - "allá / acá"; juega con el ida-vuelta , y algunos traductores de su abuelo (Freud, 1980) que piensa en esta anécdota proponen traducir por "lejos / cerca" o "no acá /acá", como si "lejos" y "no acá" designaran la misma cosa y que "cerca" y "acá" lo opuesto de esta cosa. 
Ir es ir hacia lo lejos no acá, la vuelta es el regreso hacia acá. Y el abuelo pensando que este niño que inicia su acceso al lenguaje vuelve a jugar y supera el traumatismo de la partida (y del regreso) de su madre: entonces, por el juego y el lenguaje, puede repetir el ida-vuelta de la madre, anclado en la donación-retenida del seno materno. En ciertas ocasiones, es experimentada con satisfacción, pero, sobre todo, el momento es revivido de manera fantasmática y alucinatoria. Dominando su angustia, el niño puede hacer frente a la realidad.

Igualmente, por el pensamiento del ida-vuelta, el migrante hace frente a la realidad y hace de la separación, de la distancia y de la frontera no las causas de una pérdida definitiva, sino los instrumentos para un nuevo comienzo. Y cuando son artistas, es una ocasión para una sublimación, mejor aún, una creación.

Pues, todos somos migrantes del pasado, aunque este pasado ocurriera en nuestro lugar presente; y es por lo que el problema del ir-volver nos concierne a todos, así como nos concierne todos los fort-da.

La estética del ida-vuelta es pues existencialmente inevitable.

La obra del ida-vuelta

El ida-vuelta hace su obra. Y el artista también. La prueba, la de Koerst, el hijo de Egipto, Grecia, Argentina, Argentonaiss, el hijo de Ulises, Platón, du Bellay, el hijo de Freud, Modiano, Erbetta, el hijo de su madre y de la inter-humanidad.

Las fronteras nos hacen saber que el hombre oscila entre el ir y el volver; ellas dependen de sujetos y son abordadas temporal e inconscientemente. Ellas constituyen, no tanto la humanidad, como la inter-humanidad. Es por esto que la geoestética del ir-volver nos ilumina: trabaja el inter y opera el montaje. Nosotros debemos entonces ver sus obras y plantearlas como interrogantes del ida-vuelta, hablar e interpretar, ir hacia sus fronteras,

salir? Esto mismo es la inter-humanidad.

El escritor argentino Jorge Luis Borges escribía en Funes el memorioso: "Pensó que en la hora de la muerte no habría acabado aún de clasificar todos los recuerdos de la niñez19.

Los artistas tampoco... ¡Estética nos tienes agarrados!

Ida-vuelta

Notas

1. Franco Ferrarotti (1990), Histoire et histoires de vie, Paris, Klincksieck.

2. Nota de la coord.: Se hace referencia a lo descripto por Sigmund Freud en Más allá del principio del placer acerca del juego que se realiza con los niños pequeños relativos a pérdida y aparición.

3. La Fontaine, Le loup et l'agneau. De nuevo una historia de pareja.

4. Alejandro Erbetta (2014), Frontières et mémoires, Paris, L'Harmattan, collection RETINA. CRÉATION.

5. Eric Bonnet \& François Soulages (dir.) (2014), Frontières \& artistes. Espace public, (post) colonialisme \& mobilité en Méditerranée, (dir.), Paris, L'Harmattan, collection Local \& Global.

6. François Soulages (dir.) (2011), La ville et les arts, Paris, L'Harmattan, coll. Eidos, Série RETINA, Paris, ch. 1 "Histoire de la philosophie, philosophie, esthétique, histoire de l'art \& histoire".

7. In Le Monde, 21 avril 2012, p. 19.

8. Ibid.

9. Variété IV.

10. Eric Bonnet, François Soulages \& Julian Zevallos (dir.) (2014), Memoria territorial y patrimonial. Artes \&

Fronteras, (dir.), Lima, Universidad Nacional Mayor de San Marcos Fondo Editorial.

11. François Soulages (dir.) (2014), Mondialisation \& frontières. Arts, cultures \& politiques, Paris, L'Harmattan, coll. Local \& Global. Nota de la coord : El autor hace referencia al reconocido Diccionario Crítico de la

Revolución Francesa dirigido por Mona Ozouf y Françoise Furet.

12. Cf. Ch. 1 «Photographie-contemporaine \& art-contemporain», in Photographie contemporaine et art contemporain, François Soulages (dir.) (2012), Paris, Klincksieck.

13. Leer Géoartistique \& Géopolitique. Frontières 1, François Soulages (dir.) (2012), Paris, L'Harmattan, Collection Local \& Global: Ch. 11 Le corps à l'épreuve des frontières: Barbed Hula de Sigalit Landau, Sandrine Le Corre, Ch. 12 Le numérique au service d'une méta-réalité: Border Lines d'Alexis Cordesse, Zoé Forget, et Ch.

13 Le mur médiatique israélo-palestinien, Gary Burgi.

14. Op cit., idem.

15. Nota de la coord.: en alemán: hay.

16. Regla terminológica: llamemos "acto fotográfico" al corto tiempo en la toma, "acción fotográfica" al hecho de concebir, realizar y comunicar una foto "metafotográfico" a todo lo que se dice y a veces se hace en cuanto a una foto durante su concepción, su realización, su comunicación y su recepción, "material fotográfico" al aparato, al film, la matriz numérica, el papel, etc...

17. Regla terminológica: califiquemos de "sin-arte" una realidad o una cosa que se realiza sin proyecto ni voluntad artística.

18. Char (R.)(1974), "Les compagnons dans le jardin", in Au-dessus du vent, in La Parole en archipel, in Les Matinaux (suivi de la Parole en archipel), Paris, Gallimard/poésie, $n^{\circ} 38$, p. 153.

19. Borges Jorge Luis (1974), Fictions, Paris, Gallimard, folio, p. 141. (Obras completas (1974), Buenos Aires:

Emecé, p. 489.) 
Barguet, P. (1967). Le Livre des Morts des Anciens Égyptiens. Paris: Éditions du Cerf, Fragmentos del capítulo 89 en la traducción de Paul Barguet.

Héraclite (1986). Fragments, trad. M Conche. Paris: PUF.

Héraclite, Fragments, $n^{\circ} 105$, in Battistini, Trois présocratiques. Paris: Gallimard.

Homère (1992). L’Odyssée, chant X, vers 490-1, trad. Philippe Jacottet. Paris: La Découverte.

Freud, S. (1980). "Principe du Plaisir et Névrose traumatique. Principe du Plaisir et Jeux d'enfants", en Au-delà du principe de plaisir. Paris: Payot.

Foucault, M. (1966). Les mots et les choses. Paris: Gallimard.

Modiano, P. (1980). Villa Triste. Paris: Gallimard, Folio.

Modiano, P. (2001). La Petite Bijou. Paris: Gallimard.

Modiano, P. (2010). L'horizon. Paris: Gallimard.

Modiano, P. (2010). Du plus loin de l'oubli. Paris: Gallimard, Folio.

Modiano, P. (2013). "Un pedigree" en Romans. Paris: Gallimard, Quarto.

Modiano, P. (2013). “Livret de famille” en Romans. Paris: Gallimard, Quarto.

Modiano, P. (2013). "Avant-Propos”, en Romans. Paris: Gallimard, Quarto.

Modiano, P. (2013). "Dora Bruder", en Romans. Paris: Gallimard, Quarto.

Modiano, P. (2014). Pour que tu ne te perdes pas dans le quartier. Paris: Gallimard.

Parménide, De la Nature, trad. J. Voilquin, in Les Penseurs grecs avant Socrate. Paris: Garnier- Flammarion.

Platon (1976). Le Théétète, 189 e. Paris: Les Belles Lettres.

Soulages, F. (2014). Le corps-internet. Sofia: Editions Ciela, collection Liber Liber.

Soulages, F. (2015). Les frontières des langues. Paris: L'Harmattan.

Traducción: Pedro San Gines

Revisión: Juan Manuel Perez y Alejandra Niedermaier.

Abstract: This article traces a path about the concept of border and the effects of the different migration phenomena on subjectivity through different aesthetics manifestations, and specially, photography.

Key words: borders - bodies - universal - geoaesthetics - photography.

Resumo: Através de diferentes manifestações estéticas e em especial da fotografia se apresenta um percurso sobre o conceito de fronteira e sobre os efeitos dos diferentes fenômenos migratórios sobre a subjetividade.

Palavras chave: fronteiras - corpos - universalização - geoestética - fotografia.

Resumen: A través de diferentes manifestaciones estéticas y en especial de la fotografía se realiza un recorrido acerca del concepto de frontera y de los efectos de los distintos fenómenos migratorios sobre la subjetividad.

Geoestética de idas-vueltas (a modo de introducción) fue publicado de la página 23 a página44 en Cuadernos del Centro de Estudios de Diseño y Comunicación № 59 